\title{
Urinary hormone analysis as a diagnostic tool to evaluate the ovarian function of female gorillas (Gorilla gorilla)
}

\author{
N. M. Czekala, J. F. Roser*, R. B. Mortensen‡, T. Reichard§ and \\ B. L. Lasley† \\ Research Department, Zoological Society of San Diego, San Diego, CA 92112; Departments of \\ * Animal Science and + Reproduction, University of California-Davis, Davis, CA 95616; \\ $\Varangle$ Monoclonal Antibodies, Inc., Mountain View, CA 94043; and \$Toledo Zoological Society, \\ Toledo, OH 43609, U.S.A.
}

\begin{abstract}
Summary. Daily urine samples were collected from 4 adult female gorillas over 7 menstrual cycles. Urinary oestrone conjugate and pregnanediol-3-glucuronide (PDG) were measured by radioimmunoassay; LH was measured by enzyme immunoassay and each hormone was indexed by creatinine. The quantity of urinary LH during the ovulatory surge was positively correlated with the quantity of PDG excreted during the luteal phase $(r=0.87, P=0.0013)$. The observations indicate a relationship between the quality of the LH surge and the levels of PDG in the luteal phase and suggest that both the LH surge and subsequent luteal phase function may be predictable from the oestrogen excretion profile during the follicular phase.
\end{abstract}

Keywords: gorilla; oestrogen; progesterone; LH; luteal function

\section{Introduction}

Pregnancies and births of infants are relatively rare events among gorillas that are maintained in breeding situations in the United States. In an evaluation of ovulatory ovarian cycles, assessed by measurements of steroids in urine, Mitchell et al. (1982a) indicated that a post-ovulatory or lutealphase defect may be responsible for some of the reduced fertility in this species.

To investigate this possibility further, a practical assay for urinary luteinizing hormone (LH) was developed and applied. The LH measurements together with simultaneous measurements of ovarian oestrogen and progesterone excretion were used to assess the relationship between ovarian and pituitary hormones in the gorilla menstrual cycle. The results of this study are intended to provide empirical evidence regarding the relationship between pituitary and ovarian hormone excretion as they are applied as indicators of normal ovarian function in gorillas and related species.

\section{Materials and Methods}

\section{Animals and sample collection}

Daily urine samples $(2 \mathrm{ml})$ were collected from the cage floor from 4 mature female gorillas. Three of the gorillas are housed at the Toledo Zoo ( $P$, 29 years old; $H, 14$ years old; and $M, 12$ years old) and Gorilla K (12 years old) is housed at the San Diego Zoo. The Toledo gorillas were all housed and copulated with an adult male gorilla known to have achieved at least one conception and with normal motile spermatozoa after electroejaculation. The last offspring of Gorilla P was in 1971; Gorilla $\mathrm{H}$ has not reproduced; Gorilla $\mathbf{M}$ has subsequently conceived with another male and delivered a normal infant; and Gorilla $\mathrm{K}$ has regularly copulated with a fertile male gorilla since her arrival ( 1 year) with no indication of conception or resulting offspring.

Menstruation was monitored by measuring blood in the urine using Hemastix (Miles Laboratories, Elkhart, IN, U.S.A.). Urine samples were frozen as soon as possible and kept frozen until assay. All hormone values were indexed by individual creatinine concentrations (Taussky, 1954) to correct for variation in urine concentration. 


\section{Oestrone conjugate assay}

Urinary oestrone conjugates were analysed by radioimmunoassay as previously described (Shideler et al., 1983). Briefly, $0.01 \mathrm{ml}$ undiluted urine was combined with $0.29 \mathrm{ml}$ Tris assay buffer $\mathrm{pH} 8.4(0.1 \mathrm{M} \mathrm{Tris,} 0.9 \% \mathrm{NaCl}, 0.1 \%$ $\mathrm{NaN}_{3}, 0 \cdot 1 \%$ gelatin). Antiserum which cross-reacts equally with oestrone sulphate and oestrone glucuronide (antioestrone glucuronide, $0.1 \mathrm{ml}, \mathrm{l}: 5000 ; \mathrm{D}$. Collins, Emory University) and tritiated oestrone sulphate $(0 \cdot 1 \mathrm{ml}$, 7000 c.p.m., sp. act. $55 \mathrm{Ci} / \mathrm{mmol}$ : New England Nuclear, Boston, MA, U.S.A.) were added to the urine and standard samples ( $30-500 \mathrm{pg}$ oestrone sulphate). The assay was incubated at $15^{\circ} \mathrm{C}$ for $\mathrm{I} \mathrm{h}$. Charcoal-dextran $(0.3 \mathrm{ml}, 0.625 \%$ charcoal Norite A, $0.0625 \%$ in $0.1 \mathrm{M}$-phosphate buffer $\mathrm{pH} 7.0$ ) was used to separate bound and free steroid during a 30 -min incubation at $15^{\circ} \mathrm{C}$. After centrifugation for $10 \mathrm{~min}$ the supernatants were mixed with Ready Solv HP (Beckman, Fullerton, CA, U.S.A.) and counted for $5 \mathrm{~min}$ each. The interassay coefficient of variation was $9 \cdot 1 \%$ at $33 \%$ binding. The intra-assay coefficient of variation was $4 \%$ and $1 \%$ at $22 \%$ and $65 \%$ binding respectively. Sensitivity of the assay (zero minus $2 \times$ s.d.) was $39 \mathrm{pg}$. Recovery of added oestrone sulphate $(0 \cdot 15-1 \cdot 25 \mathrm{ng})$ to urine ranged from 105 to $112 \%$ (slope $=0.91$ ).

\section{Pregnanediol-3-glucuronide assay}

Urinary pregnanediol-3-glucuronide (PDG) was analysed as described by Mitchell et al. (1982b). Undiluted urine $(0.0001 \mathrm{ml})$ was combined with $0.1999 \mathrm{ml} 0.1 \mathrm{M}$-phosphate assay buffer $-0.1 \%$ gelatin $\mathrm{pH} 7 \cdot 0$. The PDG antiserum (No. 02/zoo, 1:18 000; Courtauld Institute, London, U.K.) cross-reacts 100\% with pregnanediol-3-glucuronide and $19.5 \%$ with pregnanediol. This was combined with tritiated PDG (Courtauld Institute; sp. act. $42 \mathrm{Ci} / \mathrm{mmol}$, 7000 c.p.m. $/ 0 \cdot 1 \mathrm{ml}$ ) and the urine or standard samples $\left(30-5000 \mathrm{pg}\right.$ ) and incubated overnight at $15^{\circ} \mathrm{C}$. Bound and free steroid were separated by addition of $0.5 \mathrm{ml}$ charcoal-dextran and a $45-\mathrm{min}$ incubation at $15^{\circ} \mathrm{C}$. After centrifugation the supernatant was counted in Ready Solv-HP. Interassay coefficient of variation was $12 \%$ at $48 \%$ binding and $20 \%$ at $78 \%$ binding. Intra-assay coefficient of variation was $5 \%$ and $2 \%$ at $47 \%$ and $79 \%$ binding respectively. Assay sensitivity was $78 \mathrm{pg}$. PDG (0.15-1.25 ng) added to urine was recovered between $86 \%$ to $98 \%($ slope $=0.98)$.

\section{LH assay}

Monoclonal antibodies. Monoclonal antibodies with affinities for human luteinizing hormone (hLH) were pro-

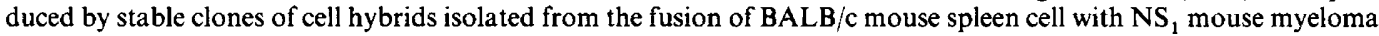
cells (Milstein \& Kohler, 1975). Mice were immunized with hLH (Parlow) or human chorionic gonadotrophin (hCG: Organon, East Orange, NJ) over a period of several weeks. Specific mice were selected for fusion when serum titres were at least 1:1000 at 50\% maximum binding in specific radioimmunoassays (RIA) for hLH and hCG. After fusion and screening of cell hybrids for specific antibodies, positive hybrids were cloned and injected into pristine primed mice for ascites antibody production (Leak et al., 1985). The two antibodies, anti-hLH (102G $\left.\mathrm{G}_{11}\right)$ and anti-hCG $\left(716 \mathrm{G}_{11}\right)$, were purified by passage through a protein $\mathrm{A}$-sepharose affinity column (Ey et al., 1978). Clone $102 \mathrm{G}_{11}$ was found to be a monoclonal $\mathrm{IgG}_{1}$ by immunoelectrophoresis and by double diffusion in agarose gels with subclassspecific antisera. Clone $716 G_{11}$ appeared to be $I g G_{1}$ based on elution patterns generated by the protein $A-s e p h a r o s e$ column (Ey et al., 1978).

Characterization of antibodies by $R I A$. The purified antibodies were evaluated in a competitive overnight RIA system previously described (Wada et al., 1982). Briefly, unlabelled hormone in serum was added to tracer and antibody, incubated overnight at room temperature and precipitated with polyethylene glycol 6000 (200 g/l) in place of the second antibody. To characterize Clone $102 \mathrm{G}_{11}$ hLH (Parlow 9/80) was used as the tracer and standard. To characterize Clone $716 \mathrm{G}_{11}$, hCG (Calbiochem, Cat no. 869031) and hLH (Parlow 9/30) were used both as the tracer and standard.

The association constants $\left(K_{\mathrm{a}}\right)$ were calculated by Scatchard analysis (Scatchard, 1949) of the data from RIA displacement experiments and found to be approximately $2 \times 10^{11} \mathrm{l} / \mathrm{M}$ for Clone $102 \mathrm{G}_{11}$ and $3 \times 10^{9} 1 / \mathrm{M}$ for Clone $716 \mathrm{G}_{11}$.

Cross-reactions of the related hormones in the RIA systems were determined by displacement of labelled hormone by cross-reacting hormone. Percentage cross-reactivity was calculated from amount of hormone causing half displacement $\left(\mathrm{ED}_{50}\right)$ of tracer-labelled hormone on a weight-ratio basis: i.e. $\left[\mathrm{ED}_{50} \mathrm{LH}(\mathrm{ng}) / \mathrm{ED}_{50} \mathrm{FSH}(\mathrm{ng})\right] \times 100=\%$ cross-reactivity of FSH in LH assay system. Cross-reactivities of Clone $102 \mathrm{G}_{11}$ with $\mathrm{hFSH}$ and hTSH were $0.9 \%$ and $18.4 \%$ respectively. Cross-reactivities of Clone $716 \mathrm{G}_{11}$ with $\mathrm{hFSH}$ and hTSH were $91 \%$ and $141 \%$ respectively (hLH as trace). Minimal detectable dose at $10 \%$ displacement was $0.2 \mathrm{ng} \mathrm{hLH} / \mathrm{ml}$ for Clone $102 \mathrm{G}_{11}$ and $18 \mathrm{ng} \mathrm{hLH} / \mathrm{ml}$ for Clone $716 G_{11}$.

Coupling of antibodies to alkaline phosphatase. The purified monoclonal antibody, Clone $716 \mathrm{G}_{11}$, was coupled to alkaline phosphatase (Sigma Chemical Co., St Louis, MO, U.S.A.) by the modified two-step method described by O'Sullivan \& Marks (1981). Briefly, 20000 units of alkaline phosphatase were dialysed against 6 litres of a phosphatebuffered saline (PBS) pH 7.0 overnight at $4^{\circ} \mathrm{C}$. The alkaline phosphatase solution was adjusted with $\mathrm{PBS}$ to $10 \mathrm{mg} / \mathrm{ml}$ 


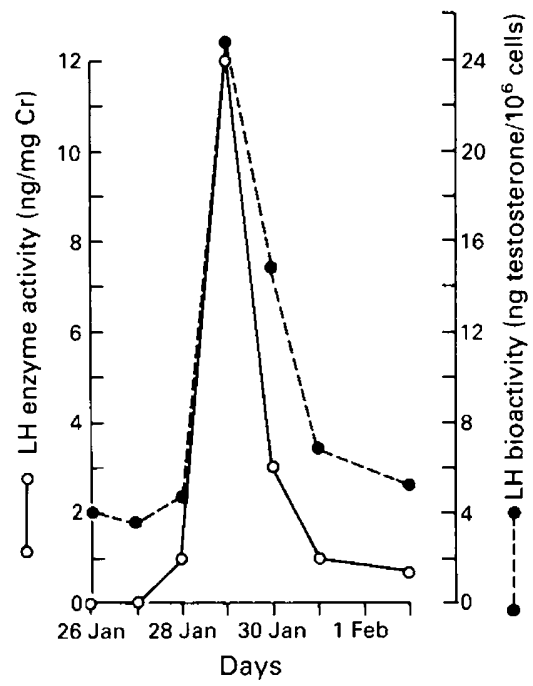

Fig. 1. Measurements of daily urine from one gorilla (M) during the mid-cycle. The LH surge is compared using the LH enzymeimmunoassay techniques and the rat Leydig cell bioassay for bioactive $\mathrm{LH}$. Both methods indicate that peak LH concentration is on 29 January and follow a similar pattern.

in a total volume of $3 \mathrm{ml}$. Exactly $0.2 \mathrm{ml}$ of a $4 \%$ solution of glutaraldehyde in PBS was added slowly with gentle mixing. The glutaraldehyde alkaline phosphatase solution was incubated for exactly $50 \mathrm{~min}$ at room temperature. The mixture was loaded onto a Sephadex G-25 column $(0.7 \mathrm{~cm} \times 27 \mathrm{~cm})$ at $4^{\circ} \mathrm{C}$ to remove the glutaraldehyde. About $1 \mathrm{mg}$ antibody, IgG, was dialysed overnight in $0.7 \mathrm{M}$-carbonate buffer at $4^{\circ} \mathrm{C}$. During the coupling procedure, $0.2 \mathrm{ml}$ of dialysed IgG $(1 \mathrm{mg})$ was slowly added to a solution of $4 \mathrm{mg}$ purified alkaline phosphatase in $0.6 \mathrm{ml}$ PBS. The reaction was allowed to proceed at room temperature for $8 \mathrm{~h}$. The solution was loaded onto an ultrogel ACA-34 column $\left(0.7 \mathrm{~cm} \times 43 \mathrm{~cm}\right.$; LKB, Paris, France) equilibrated at $4^{\circ} \mathrm{C}$ with a $0.05 \mathrm{M}$-Tris buffer $\mathrm{pH} 7.2$, containing $0.9 \%(\mathrm{w} / \mathrm{v})$ $\mathrm{NaCl}$ and $0.001 \mathrm{M}-\mathrm{MgCl}_{2}$. Flow rate was adjusted to $0.6 \mathrm{ml} / 5 \mathrm{~min}$. Fractions were tested for IgG-alkaline phosphatase activity in an enzyme-linked immunosorbent assay (ELISA) (see below). Positive fractions were pooled with the addition of BSA ( $1 \% \mathrm{w} / \mathrm{v}$; Fraction V, Sigma) and parabens $\left(10 \%\right.$ methyl-propyl parabens in $\mathrm{H}_{2} \mathrm{O} ; 0.01 \% \mathrm{v} / \mathrm{v}$; Sigma). The solution was stored at $-20^{\circ} \mathrm{C}$ until needed.

The validity of the enzyme-linked immunosorbent assay to monitor LH activity in gorilla urine was assessed by the rat Leydig cell bioassay for LH as described by Ramachandran \& Sairam (1975). Similar LH patterns were obtained by both assay systems (Fig. 1).

ELISA for LH. Capture antibody (Clone $102 \mathrm{G}_{11}$ : Monoclonal Antibodies Inc., Mt View, CA) was diluted to $2 \mu \mathrm{g} / \mathrm{ml}$ with phosphate-buffered saline (0.01 M-PBS $\mathrm{pH} 7.0$ ). Then 96-well microtitre plates (Immulon I, Dynatek) were coated, $0.2 \mathrm{ml} /$ well, with the diluted capture antibody and incubated overnight at room temperature. After incubation the plates were emptied and washed twice with wash buffer $(17.5 \mathrm{~g} \mathrm{NaCl}, 0.8 \mathrm{ml}$ Tween $20 / 2$ litres deionized water). Plates were inverted and dessicated at room temperature. To each well in triplicate was added $0.2 \mathrm{ml}$ standard (Parlow 9/80) in a dose from 0.25 to $16 \mathrm{ng} / \mathrm{ml}$. Samples $(0.1 \mathrm{ml}$ urine) were assayed in duplicate, and the plate was incubated for $2 \mathrm{~h}$ at room temperature. The plate was washed 3 times with wash buffer and $0.150 \mathrm{ml}$ Clone $716 \mathrm{G}_{11}-$ alkaline phosphatase (1:1000 in assay buffer) was added to each well and incubated for $1 \mathrm{~h}$ at room temperature. After incubation the plate was washed 3 times with wash buffer and $0.2 \mathrm{ml}$ substrate solution, 5-bromo-4-chloro-3indolyphosphate (BCIP, Sigma) was added to each well. Incubation was carried out at room temperature for 25-50 min and plates were read on a Dynatek plate reader at an optical density of $630 \mathrm{~nm}$. The interassay coefficient of variation for $13 \mathrm{ng}$ was $11 \%$ and for $4 \mathrm{ng}$ was $9 \%$. Intra-assay coefficient of variation at $1 \mathrm{ng}$ was $6 \%$ and at $8 \mathrm{ng}$ was $2 \%$. hLH (4 ng) added to baseline urine was recovered at $100 \%$. Assay sensitivity was $0.5 \mathrm{ng} / \mathrm{ml}$.

\section{Statistics}

The area under the curve was analysed by triangulation. LH area was calculated from baseline to baseline $(n=4-6$ days) during the ovulatory peak. Oestrone conjugate area was calculated as Day -4 to Day 0 (oestrone conjugate peak $=$ Day 0 ). Day -4 was the first detectable elevation of oestrone conjugate above baseline levels. PDG area was calculated from Day +1 to the day before menstruation $(n=14-17)$.

Hormone values were compared using linear correlation and Student's $t$ test. All mean values are expressed as \pm s.e.m. 


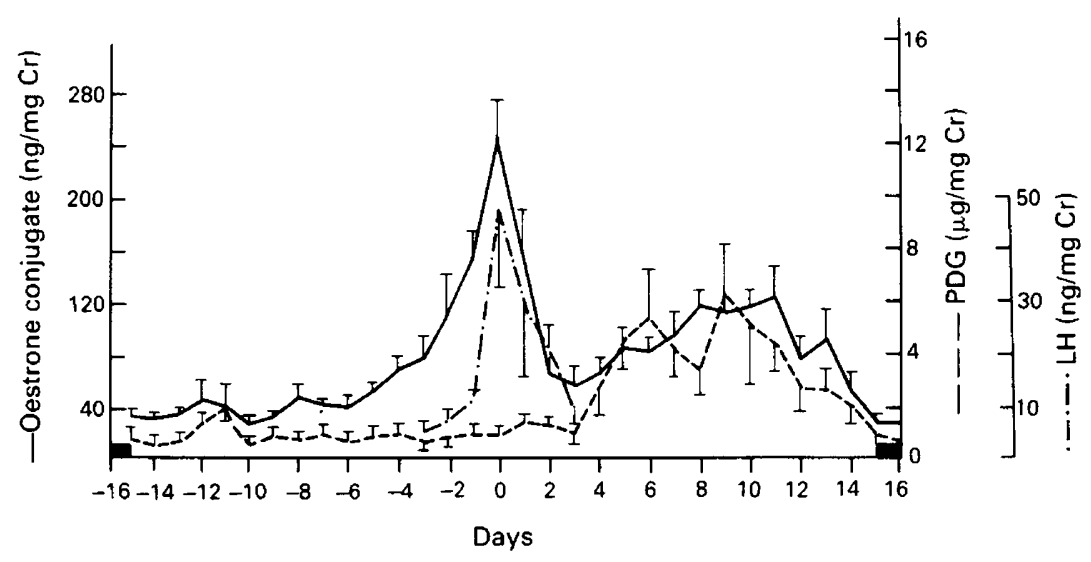

Fig. 2. Mean \pm s.e.m. daily values of urinary oestrone conjugates, PDG and LH of 4 mature female gorillas ( 7 cycles). Peak values of oestrone conjugates correspond with the peak level of LH.

\section{Results}

The composite urinary hormone profiles of oestrone conjugate, PDG and LH for 7 menstrual cycies of 4 adult female gorillas are shown in Fig. 2. Samples are aligned to the oestrone conjugate peak (Day 0). The average follicular-phase length, defined as the first day of menstruation to the peak oestrone conjugate value was 16.4 \pm 1.4 days (range 13-24 days). The average luteal-phase length, calculated as the day after the oestrone conjugate peak to the next menstruation, was $14.0 \pm 0.4$ days (range 12-15 days). The total length of the cycle was then $30.4 \pm 1.5$ days (range 27-39 days). Hormone variation between individuals was greatest for PDG excretion. An example of high PDG excretion is illustrated in Fig. 3(a) (M12/24): PDG concentrations at ovulation (day 17) rose above baseline values ( $1 \mu \mathrm{g} / \mathrm{mg}$ creatinine) to $2 \mu \mathrm{g} / \mathrm{mg}$ creatinine for 2 days, then between Day 3 and Day 10 after the LH peak a larger amount of PDG was excreted (range 5-18 $\mu \mathrm{g} / \mathrm{mg}$ creatinine). Comparison of this profile to the profile in Fig. 3(b) illustrates the variability of lutealphase PDG between individuals. A rise in PDG was not measurable in Gorilla $\mathrm{H}$, cycle 11/15 until 3 days after the $\mathrm{LH}$ peak (range 1 to $2 \mu \mathrm{g} / \mathrm{mg}$ creatinine). The duration of the peak was 7 days.

To investigate the cause of the variability of PDG excretion rates, the height and duration of the PDG profile was compared to the height-duration of the LH profile by analysing the area under the curve for each hormone (Table 1). Variation in LH excretion within an individual (coefficient of variation range $7-30 \%)$ is less than the variation between individuals $(\mathrm{CV}=48 \%)$. This is also true for PDG (within CV range 0-38\%; between $42 \%$ ), follicular-phase oestrone conjugate (within CV range $0-38 \%$; between $42 \%$ ), and luteal-phase oestrone conjugate (within CV 10-24\%; between $29 \%)$. Correlation coefficients calculated by linear correlation indicated a significant $(P=0.009)$ relationship between increased LH excretion and increased PDG excretion $(r=0.87)$. When the area under the ovulatory $\mathbf{L H}$ profile was compared to the amount of oestrone conjugate excreted during and including the 4 days before ovulation the correlation coefficient $(r=0 \cdot 88)$ indicated a significant $(P=0.008)$ relationship between the amount of oestrogen produced by the dominant follicle and the subsequent quality of the LH surge. The correlation between follicular oestrone conjugate and luteal phase PDG approached significance $(r=0.73 ; P=0.06)$. The luteal excretion of oestrone conjugate significantly correlated with both LH $(r=0.75, P=0.05)$, and follicularphase oestrone conjugate $(r=0.83, P=0.05)$, and tended to correlate with PDG $(r=0.68$; $P=0 \cdot 09)$. 


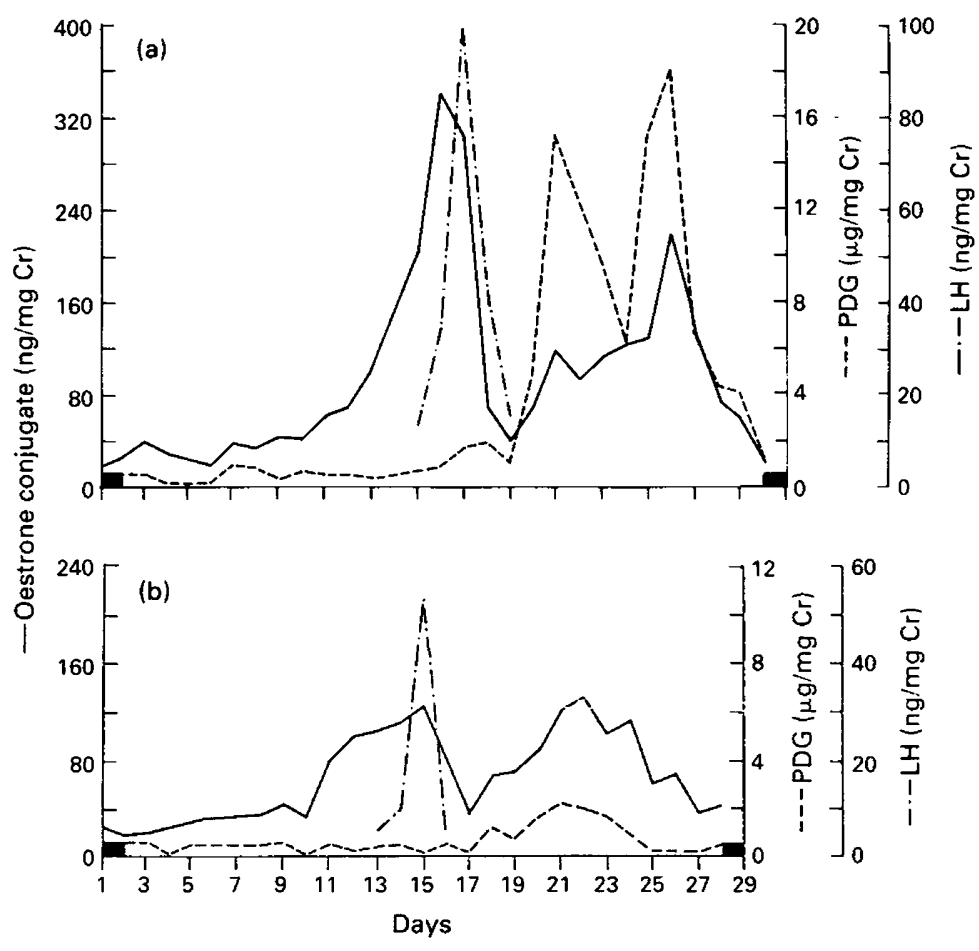

Fig. 3. Daily measurements of immunoreactive urinary oestrone conjugate, PDG and LH for (a) Gorilla M (cycle 12/24) and (b) Gorilla $\mathrm{H}$ (cycle 11/15). Solid bars denote the beginning of menstruation. Cycle length is (a) 30 days and (b) 28 days.

Table 1. Areas under the curve for hormones measured in the urine of gorillas

\begin{tabular}{crrrcc}
\hline & & & & \multicolumn{2}{c}{ Oestrone conjugate } \\
\cline { 5 - 6 } Gorilla & Cycle & LH & PDG & Follicular phase & Luteal phase \\
\hline P & $7 / 84$ & $10 \cdot 3$ & $4 \cdot 8$ & 334 & 1179 \\
$\mathrm{P}$ & $10 / 25$ & $6 \cdot 6$ & $5 \cdot 3$ & 341 & 1011 \\
$\mathrm{H}$ & $9 / 24$ & $6 \cdot 1$ & $1 \cdot 3$ & 187 & 715 \\
$\mathrm{H}$ & $11 / 15$ & $6 \cdot 8$ & $1 \cdot 3$ & 326 & 905 \\
$\mathrm{M}$ & $1 / 24$ & $16 \cdot 6$ & $6 \cdot 9$ & 715 & 1686 \\
$\mathrm{M}$ & $12 / 24$ & $19 \cdot 0$ & $10 \cdot 1$ & 593 & 1188 \\
$\mathrm{~K}$ & $8 / 14$ & $9 \cdot 4$ & $2 \cdot 7$ & 467 & 867 \\
\hline
\end{tabular}

The integrated area under the curve is shown for individual cycles for the ovulatory LH peak (baseline to baseline), luteal-phase PDG (oestrone conjugate peak to the day before the next menstruation), late follicularphase oestrone conjugates ( 4 days before and including the peak ovulatory oestrone conjugate value), and luteal-phase oestrone conjugates (oestrone conjugate nadir following ovulatory oestrone conjugate peak to the next menstruation). 


\section{Discussion}

Daily serum hormone measurements for prolonged periods are difficult to obtain in any situation and would be impossible to obtain from untractable animals like gorillas. Analysis of subtle endocrine differences in ovarian function, which may contribute to reduced fertility, however, require serial measurements through consecutive ovarian cycles. A sensitive enzymeimmunoassay for measuring gorilla $\mathbf{L H}$ in urine was therefore developed to assess ovarian and pituitary function. Previously, LH in the urine of gorillas was quantified by a lengthy and cumbersome bioassay. Two monoclonal antibodies against human gonadotrophins were found to cross-react specifically with gorilla LH which permits a more simple and rapid analysis of LH. This is the first study to use a rapid, simple and sensitive immunoassay for gorilla $\mathrm{LH}$.

The results presented here suggest that each of the three urinary metabolic profiles reflect circulating hormone. The larger LH surge, associated with the increased preovulatory oestrogen production, is consistent with the relationship of the positive effects of oestrogen in eliciting the LH surge (Sherman \& Korenman, 1974a). Similarly, the enhanced PDG profile after the larger LH surge suggests a causal relationship between the ovulatory surge of LH which has been induced by the antecedent oestrogen peak. In contrast, reduced oestrogen and LH profiles are associated with the lowered luteal-phase PDG profiles. These relationships provide the basis for the inference of an inadequate luteal phase and supports the contention of Mitchell et al. (1982a).

Sherman \& Korenman (1974b) reported that an inadequate luteal phase in women has a normal luteal length with decreased serum progesterone values. This event is accompanied by decreased follicular and mid-cycle FSH concentrations and decreased luteal progesterone, but normal serum LH. Soules et al. (1984) report an increased serum LH pulse frequency during the early follicular phase (Days 4-6) in women with an inadequate luteal phase, with pulse amplitudes slightly lower than normal. Studies relating urinary concentration of $\mathrm{LH}$ and oestrogen in the human in this context have not been reported.

In the gorilla cycles examined in this study, through urinary hormone analysis, all had luteal phases of normal length, but varied from individual to individual in the quantity of progesterone metabolite excreted during the luteal phase. When comparing the ovulatory LH peak to the amount of PDG excretion, the high correlation $(r=0.87)$ indicates a positive relationship between increased LH and increased PDG excretion and conversely indicates that diminished PDG excretion is preceded by a lower ovulatory LH surge. In addition, the equally strong relationship between LH and follicular-phase oestrogen production would be consistent with the report of Sherman \& Korenman (1974b) of depressed FSH values in the inadequate luteal-phase of women since oestrogen secretion is a direct result of FSH stimulation. It may be possible, therefore, to predict the quality of the forthcoming luteal phase by measuring oestrone conjugates and/or LH during the follicular phase. The high correlation of LH to luteal-phase oestrone conjugate concentrations $(r=0.75)$ additionally confirms the role of $\mathrm{LH}$ in stimulating the granulosa (luteal) cells during the luteal phase to produce progesterone and oestrogen. All other correlations support the contention that a marked follicular-phase oestrone conjugate rise precedes a larger LH surge and these are directly related to the amount of progesterone secreted in the luteal phase.

The present results support the claim of Mitchell et al. (1982a) that aberrant luteal excretion of PDG can be seen in captive gorillas which have reduced fertility. The inadequate luteal-phase cycles studied here also indicate a compromised follicular development, as judged by low preovulatory oestrone conjugate concentrations, which appear to have resulted in a lowered LH response by the pituitary. Therefore, urinary hormone metabolite values can be general indicators of ovarian function and may be indicators of fertility. Further studies should be designed to address the apparent imbalance in the pituitary-gonadal function and its relationship to reduced fertility in the captive gorilla.

We thank Dr A. Parlow for LH standard; Dr Del Collins for oestrone glucuronide antiserum; 
Monoclonal Antibodies, Inc. for LH testing materials; Dr David Baldwin, Hormone Research Laboratory, University of California, San Francisco for performing the rat Leydig cell assay; the gorilla keeper staffs at the San Diego Zoo, San Diego Wild Animal Park and the Toledo Zoo for their co-operation; and Susan Butler for manuscript preparation.

\section{References}

Ey, P.L., Prowse, S.J. \& Jankin, C.R. (1978) Isolation of pure $\mathrm{IgG}, \mathrm{IgG}_{2 \mathrm{a}}$ and $\mathrm{IgG}_{2 \mathrm{~b}}$ immunoglobulins from mouse serum using protein A-sepharose. Immunochemistry 15, 429-436.

Leak, L.V., Potter, M. \& Mayfield, W.J. (1985) Response of the peritoneal mesothelium to the mineral oil, pristine. Current Topics in Microbiology and Immunology 122, 221-227.

Milstein, C. \& Kohler, G. (1975) Continuous cultures of fused cells secreting antibody of pre-defined specificity. Nature, Lond. 256, 495-497.

Mitchell, W.R., Loskutoff, N.M., Czekala, N.M. \& Lasley, B.L. (1982a) Abnormal menstrual cycles in the female gorilla (Gorilla gorilla). J. Zoo Anim. Med. 13, 143-147.

Mitchell, W.R., Presley, S., Czekala, N.M. \& Lasley, B.L. (1982b) Urinary immunoreactive estrogen and pregnanediol-3-glucuronide during the normal menstrual cycle of the female lowland gorilla (Gorilla gorilla). Am. J. Primatol. 2, 167-175.

O'Sullivan, M.J. \& Marks, V. (1981) Methods for the preparation of enzyme-antibody conjugates for use in enzyme immunoassay. In Methods in Enzymology, Vol. 73 , pp. 147-166. Eds J. J. Langone \& H. Van Vunakis. Academic Press, New York.

Ramachandran, J. \& Sairam, M.R. (1975) The effects of interstitial cell-stimulating hormone, its subunits and recombinants on isolated rat leydig cells. Archs Biol. Biophys. 167, 294-300.

Scatchard, G. (1949) The attraction of protein for small molecules and ions. Ann. N.Y. Acad. Sci. 51, 660-672.
Sherman, B.M. \& Korenman, S.G. (1974a) Measurement of plasma LH, FSH, estradiol and progesterone in disorders of the human menstrual cycle: the short luteal phase. J. clin. Endocr. Metab. 38, 89-93.

Sherman, B.M. \& Korenman, S.G. (1974b) Measurement of serum LH, FSH, estradiol and progesterone in disorders of the human menstrual cycle: the inadequate luteal phase. J. clin. Endocr. Metab. 39, 145-149.

Shideler, S.E., Czekala, N.M., Kasman, L.H., Lindburg, D.G. \& Lasley, B.L. (1983) Monitoring ovulation and implantation in the lion-tailed macaque (Macaca silenus) through urinary estrone conjugate evaluations. Biol. Reprod. 29, 905-911.

Soules, M.R., Steiner, R.A., Clifton, D.K. \& Bremner, W.J. (1984) Abnormal patterns of pulsatile luteinizing hormone in women with luteal phase deficiency. Obstet. Gynecol. 63, 626-629.

Taussky, H.H. (1954) A microcolorimetric determination of creatinine in urine by the Jaffe reaction. $J$. biol. Chem. 208, 853-861.

Wada, H.G., Danisch, R.J., Baxter, S.R., Federici, M.M., Fraser, R.C., Brownmiller, L.J. \& Lankford, J.C. (1982) Enzyme immunoassay of the glycoprotein tropic hormones-choriogonadotropin, lutropin, thyrotropin - with solid-phase monoclonal antibody for the alpha-subunit and enzyme coupled monoclonal antibody specific for the beta-subunit. Clin. Chem. 28, 1862-1866.

Received 11 May 1987 